\title{
Other people's memory
}

Citation for published version (APA):

Crombag, H., Merckelbach, H. L. G. J., \& Elffers, H. (2000). Other people's memory. Psychology Crime \& Law, 6(4), 251-265. https://doi.org/10.1080/10683160008409806

Document status and date:

Published: 01/01/2000

DOI:

10.1080/10683160008409806

Document Version:

Publisher's PDF, also known as Version of record

\section{Please check the document version of this publication:}

- A submitted manuscript is the version of the article upon submission and before peer-review. There can be important differences between the submitted version and the official published version of record.

People interested in the research are advised to contact the author for the final version of the publication, or visit the DOI to the publisher's website.

- The final author version and the galley proof are versions of the publication after peer review.

- The final published version features the final layout of the paper including the volume, issue and page numbers.

Link to publication

\footnotetext{
General rights rights.

- You may freely distribute the URL identifying the publication in the public portal. please follow below link for the End User Agreement:

www.umlib.nl/taverne-license

Take down policy

If you believe that this document breaches copyright please contact us at:

repository@maastrichtuniversity.nl

providing details and we will investigate your claim.
}

Copyright and moral rights for the publications made accessible in the public portal are retained by the authors and/or other copyright owners and it is a condition of accessing publications that users recognise and abide by the legal requirements associated with these

- Users may download and print one copy of any publication from the public portal for the purpose of private study or research.

- You may not further distribute the material or use it for any profit-making activity or commercial gain

If the publication is distributed under the terms of Article $25 \mathrm{fa}$ of the Dutch Copyright Act, indicated by the "Taverne" license above, 
Psychology, Crime \& Law, Vol. 6, pp. 251-265

Reprints available directly from the Publisher

Photocopying permitted by license only
(C) 2000 OPA (Overseas Publishers Association) N.V. Published by license under the Harwood Academic Publishers imprint, part of the Gordon and Breach Publishing Group. Printed in Malaysia.

\title{
OTHER PEOPLE'S MEMORY
}

\author{
HANS CROMBAG, ${ }^{a, *}$ HARALD MERCKELBACH ${ }^{\mathrm{a}}$ and \\ HENK ELFFERS ${ }^{b}$ \\ ${ }^{\mathrm{a}}$ Maastricht University; ${ }^{\mathrm{b}}$ Erasmus University, \\ Rotterdam, The Netherlands
}

\begin{abstract}
How optimistic are people's evaluations of their own memory as compared to that of most others? To find out, we asked 563 Ss. to compare their own memory for events, faces and names to that of others. The results show that many, and especially young respondents, tend to be illusory optimistic about the power of their memory for events and faces, but not for names. The implications of this result for evaluating eyewitness reports by triers of fact in legal cases are discussed.
\end{abstract}

Key words: memory; eyewitness testimony; illusory optimism.

\section{INTRODUCTION}

There is a vast literature on the accuracy of autobiographical memory. This literature generally shows that autobiographical memory is often rather inaccurate and malleable to an amazing extent (Schacter, 1995). This raises problems, particularly in legal contexts when witnesses are asked to report from memory about events they witnessed or faces they saw at some earlier point in time. The accuracy of autobiographical memories is a matter of great concern to lawyers involved in litigation, as well as to legal psychologists consulting with these lawyers.

There is another side to this problem. Witnesses report from memory to other people, judges and - in the Anglo-American legal tradition members of juries, who then must evaluate those reports as to their veracity and accuracy. To a large extent, such evaluations will probably depend on their own idea of what is possible and probable in autobiographical memory. This, in turn, will probably depend to a considerable extent on their experience - if that is what it is - with their own memories. When listening to an eyewitness report, they may ask themselves whether under the given circumstances, they themselves would be able to remember the

\footnotetext{
* Corresponding author. P.O. Box 616,6200 MD Maastricht, The Netherlands. E-mail: Hans.Crombag@Metajur.Unimaas.nl
} 
details of such an event accurately. And when trying to decide on the value of identification evidence, they may well ask whether they themselves would be able to recognize a face under the given circumstances. We therefore submit that the evaluation of eyewitness reports by judges and members of juries critically depends on their ideas about what is and what is not possible or probable in their own autobiographical memory, and how they think their own autobiographical memory compares to that of others.

Of course, other factors may influence whether and to what extent one believes an eyewitness report, such as the behavior and appearance of the person testifying, and the kind of person one knows or believes the witness to be. Studies show that appearance (Winkel and Vrij, 1990) and behavior, in particular the witness's apparent confidence while testifying (Deffenbacher, 1980), are poor predictors of their accuracy and veracity, but evenso triers of fact often rely on such factors in some, probably idiosyncratic, way to gauge a witness's believability. In daily life, the kind of person we know or believe a person to be is probably an important factor in deciding whether to believe such a person when reporting something that happened at some earlier point in time. In legal settings, triers of fact at best have limited, if any, information about the intelligence and uprightness of a witness, but the inclination to infer these from a witness's appearance and behavior may be irresistible to many. Still, what you think, for whatever reason, is possible and probable in autobiographical memory may be the more important factor in judging the believability of testimony offered to you. This issue has, to our knowledge, not yet been addressed in the literature.

This study explores what people think of the powers of other people's memory by making them compare it to their own. The present study is not predicated on the assumption that people's beliefs about their memory reflects their actual memory performance. Ponds (1998) and Gilewski and Zelinski (1986) already noted that there is no straightforward relation between self-reported memory functioning and objective memory performance. The correlations between these two variable are either non-significant or, at best, modest. Apparently, people really do not have a realistic standard for such a comparison. But what other standard do they have? The issue is important because if triers of fact in legal cases - be it judges or members of juries - think that their own autobiographical memory is worse than that of the average other person, they may well tend to overestimate the accuracy of eyewitness testimony presented to them, and believe more from others than they think themselves capable of. And vice versa, if triers of fact in legal cases think that their own autobiographical memory is superior to that of the average other person, they may well underestimate the accuracy of eyewitness testimony. When asked to compare your own memory with that of others, the best, and certainly most 
prudent, answer is to say that it is probably neither better nor worse. You may have a valid reason to think that your memory is better or worse than that of a particular individual you know well, but surely not that your memory is better or worse than that of most other people.

Trying to choose a priori between these two possibilities, one probably best puts one's money on the hypothesis that people generally tend to overestimate the power of their own autobiographical memory in comparison to that of the average other person. Our reason for expecting this is that studies on so-called 'self-related biases' have shown that people "typically report that they possess positive characteristics to a higher, and negative characteristics to a lower, degree than the average other or most others" (Hoorens, 1993). This phenomenon is known as 'illusory optimism'. If we assume that most people consider a strong autobiographical memory a positive characteristic, we would expect that such an aboveaverage effect will also occur when people are asked to compare the power of their own autobiographical memory to that of others.

We can think of a reason for the opposite prediction though. If one assumes that people are usually more aware of their own memory lapses than those of others - which seems not an altogether unreasonable assumption - one would expect a tendency toward, what one might call, 'illusory pessimism'. This study explores whether people display illusory optimism or pessimism when they compare their own autobiographical memory to that of "most other people". By instructing our subjects in this manner we intended to activate their 'availability heuristic' (Nisbett and Ross, 1980), while at the same time allowing them to exclude from their reference group extreme cases at both sides of the distribution.

\section{METHOD}

\section{Questionnaires}

A one-page questionnaire in Dutch was presented to a large number of subjects, in translation reading as follows (capitals in the original):

Not everybody has an equally good memory, it seems. Some can remember without great difficulty a trip they made some years ago, what day it was, who took part in it, and what happened. Others have great difficulty remembering how they spent their weekend three weeks ago. We do not teally know how many people have a good memory, and how many a bad memory. The following questions have to do with this.

1. When you compare yourself with other people you know - members of your family, friends and colleagues - how good do you think your autobiographical memory is? We are not interested in how well you can 
memorize schoolish things, but in things that happened to you. Do you think that your autobiographical memory is:

a. BETTER than that of most other people you know?

b. NEITHER BETTER NOR WORSE than that of most other people you know?

c. WORSE than that of most other people you know?

(Circle one letter)

2. A special case is remembering faces and names. Some people definitely know someone else after having met that person only once, whereas others introduce themselves repeatedly to the same person because they apparently have forgotten having met that person before.

How about you? When you compare yourself with other people you know members of your family, friends and colleagues - how good do you think your memory for FACES AND NAMES is? Do you think that your memory for faces and names is:

a. BETTER than that of most other people you know?

b. NEITHER BETTER NOR WORSE than that of most other people you know?

c. WORSE than that of most other people you know?

(Circle one letter)

Subjects were also asked to indicate their gender and age. Note that the reference group "most people you know" is not only given in the stem of the questions, but is also repeated in each of the possible answers.

Obviously, this questionnaire is a rather crude one. When asked about the quality of your memory, the realistic reaction would be a counter-question: "I have several memory systems; which one are you interested in?" Visual memory (e.g., for faces), and auditory memory (e.g., for names) are really quite different psychological functions, if only because they are served by different cerebral systems (Farah, Wilson, Drain and Tanaka, 1998), even located in different hemispheres (Pöppel, 1988). The fact that face recognition may be selectively impaired, as in prosopagnosia, corroborates this (Weiskrantz, 1997). Subjectively though, for most of us memory is a more or less unitary function. We have quite definite ideas about the quality of our own 'memory' and those of other people we know well. So most of us naively answer questions like the ones in the above questionnaire. Not everybody though. Of the 563 respondents to the first question, 18 refused to answer the second one, adding in the margin remarks pertaining to the difference between memory for faces and names. They were right, of course. 
To remedy this anomaly in the first questionnaire, to at least a certain extent, a second questionnaire was devised, which (in Dutch) read as follows (capitals in the original):

It is rather embarassing when you meet someone who says you have met him before, while you cannot remember this. It happens to everybody occasionally, but to some more than to others. Some people appear to be good at remembering faces, others at remembering names, while for others it does not make a difference. How about you?

1. When it comes to remembering FACES, how good are you compared to others?

a. BETTER than most others.

b. NEITHER BETTER NOR WORSE than most others.

c. WORSE than most others.

(Circle one letter)

2. When it comes to remembering NAMES, how good are you compared to others?

a. BETTER than most others.

b. NEITHER BETTER NOR WORSE than most others.

c. WORSE than most others.

(Circle one letter)

3. At what are you better: remembering faces OR names?

a. BETTER IN NAMES than in faces.

b. NO DIFFERENCE: equally good/bad in names as in faces.

c. BETTER IN FACES than in names.

(Circle one letter)

Again, respondents were asked to indicate their gender and age. At first glance, the third question may seem redundant with the previous two, but that is not the case. You can believe that both your memory for faces and your memory for names are better/worse than that of most others and still believe also that your memory for faces is better/worse than that for names.

\section{Subjects}

The first questionnaire was administered to 563 subjects, 287 men and 276 women, all of them in some way or other connected with Maastricht University. They were students, staff members of various ages, and a group of pensioners taking evening classes especially organized for them. The students and staff members were recruited from different university departments, but as there were no significant differences between respondents 


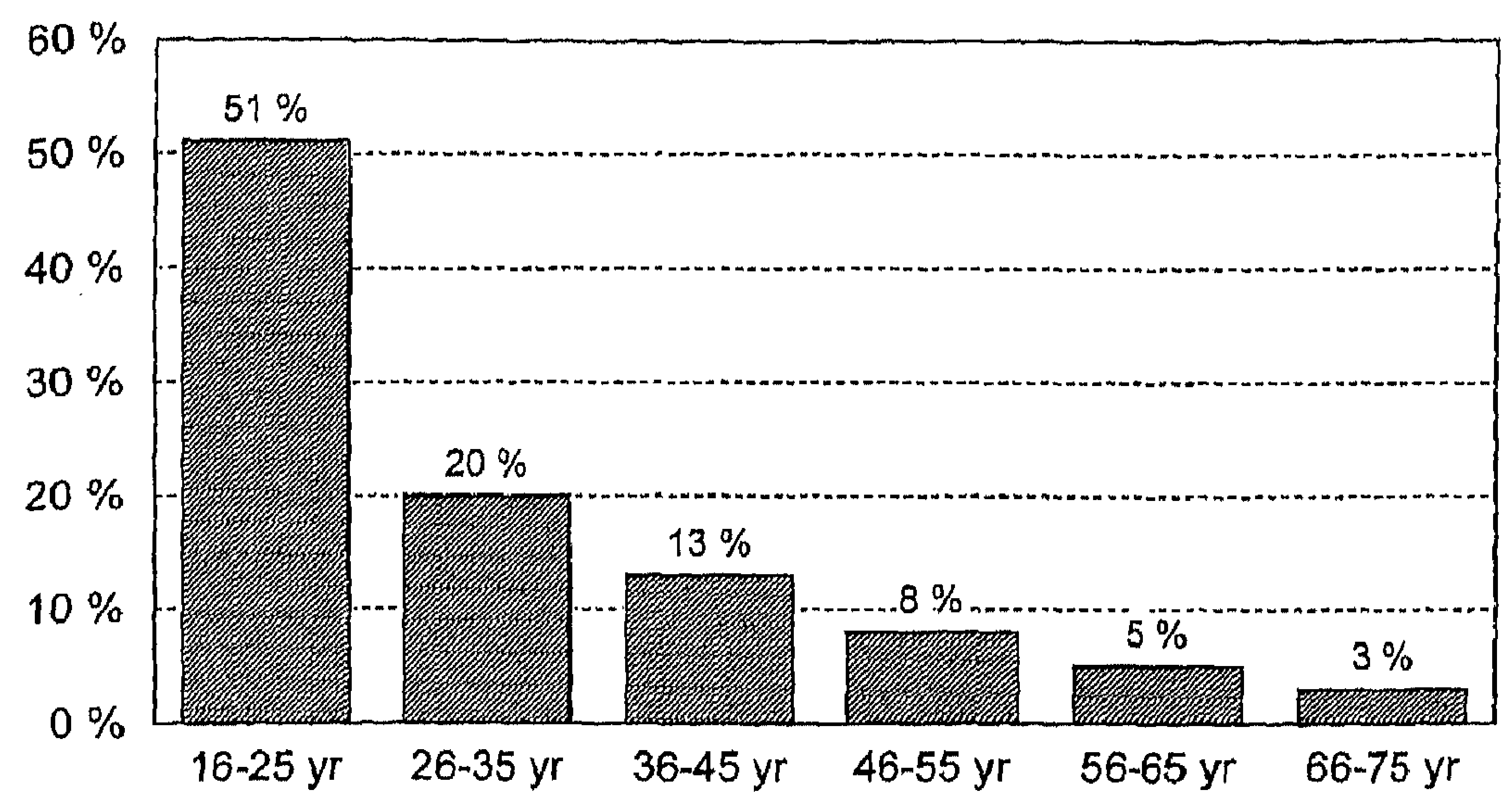

Figure 1 Distribution of age of respondents to questionnaite $1(n=563)$.

from different departments, this distinction will be ignored. Our intention was to obtain as much variation as possible in the ages of the respondents. Figure 1 shows how (un)successful this attempt turned out to be.

The figure shows that the age distribution in our sample regrettably was heavily skewed towards the lower side. Elderly people are difficult to recruit. Moreover, it seemed wise only to recruit elderly people whose memories we could rely on to function more or less normal for their age. This is why we recruited them among people who were still intellectually active, witnessing their participation in the 'HOVO program', the acronym standing for the program of 'higher education for the elderly'.

The second questionnaire was answered by 62 students, 28 men and 34 women, all between the ages of 21 and 26 .

\section{RESULTS}

\section{Questionnaire 1}

Table 1 shows the frequencies and percentages of respondents who choose each of the three possible answers to the questions in questionnaire 1. For both questions about half of the respondents choose the prudent answer, which is that they think that their own memory is probably neither better nor worse than that of most other people they know.

The other half of the respondents think that their memory is either better or worse than that of most other people. Of those who think that their memory is different from that of most other people they know, about half think their memory for faces and names is better, while the other half think 
Table 1 Own memory compared to memory of others: frequencies (and percentages) of responses.

\begin{tabular}{lrl}
\hline & Events & Faces and names \\
\hline Better & $159(28)$ & $161(30)$ \\
Equal & $326(58)$ & $251(46)$ \\
Worse & $78(14)$ & $133(24)$ \\
Total & $563(100)$ & $545(100)$ \\
\hline
\end{tabular}

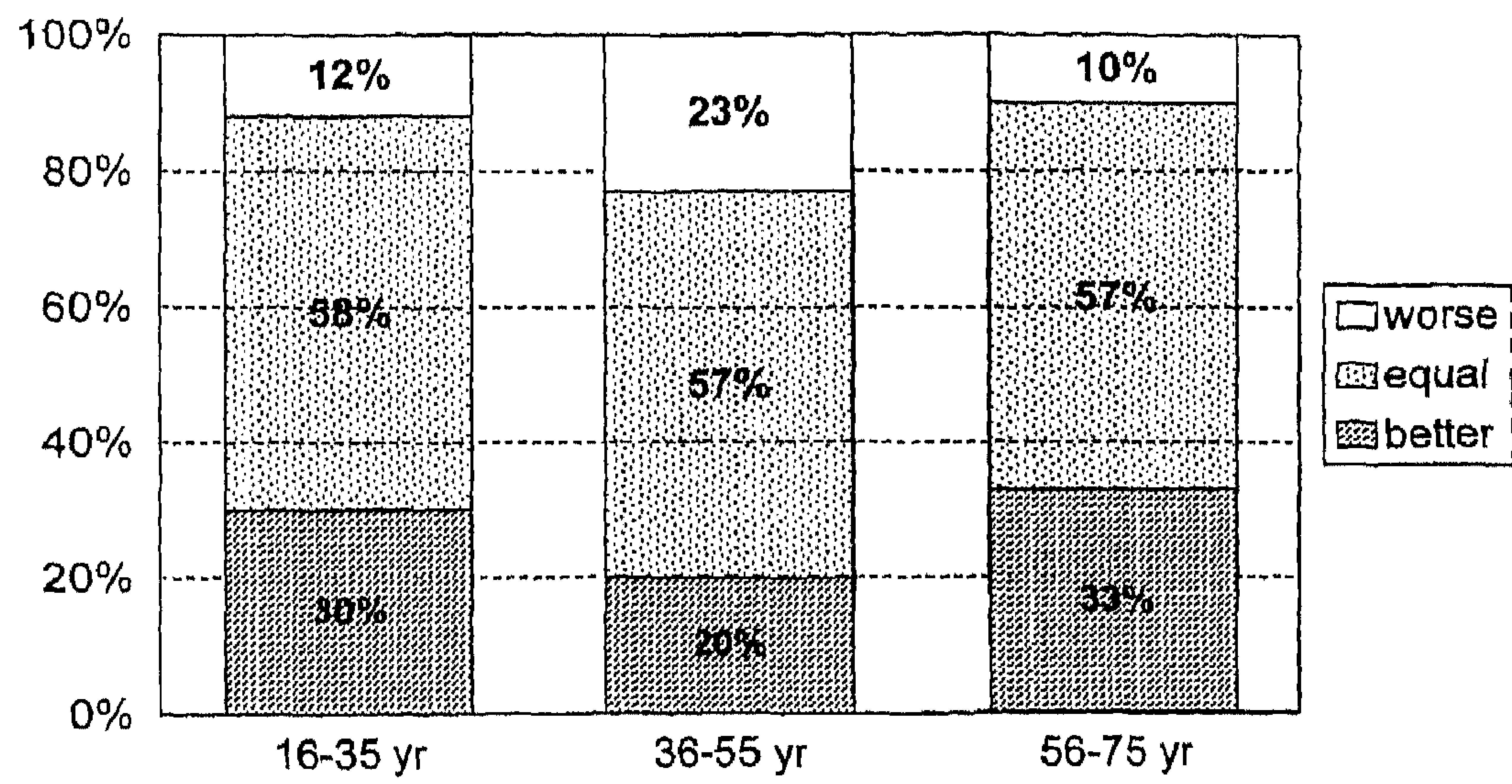

Figure 2 Memory for events, in age groups $(n=563)$.

it is worse (Wilcoxon's signed ranks test for symmetry around the midpoint of the distribution does not reject symmetry, $p=0.102$ ). However, for memory of events things are different: twice as many respondents think their memory for events is better than that of most other people than there are respondents who think it is worse (Wilcoxon's signed ranks test: $p<0.001)$. So, for events, a considerable number of the respondents are prone to illusory optimism.

The next question to consider is whether age makes a difference. Because Figure 1 showed that the higher age classes have only few respondents, we merged the age classes into three new classes: 16-35 years, 36-55 years, and 56-75 years. Figure 2 shows the distribution of the answers 'better', 'equal', and 'worse' across age groups for the question about memory for events in questionnaire 1. In all age groups, fair majorities rate their own memory for events as neither better nor worse than that of most others. For those who perceive a difference, illusory optimism is 


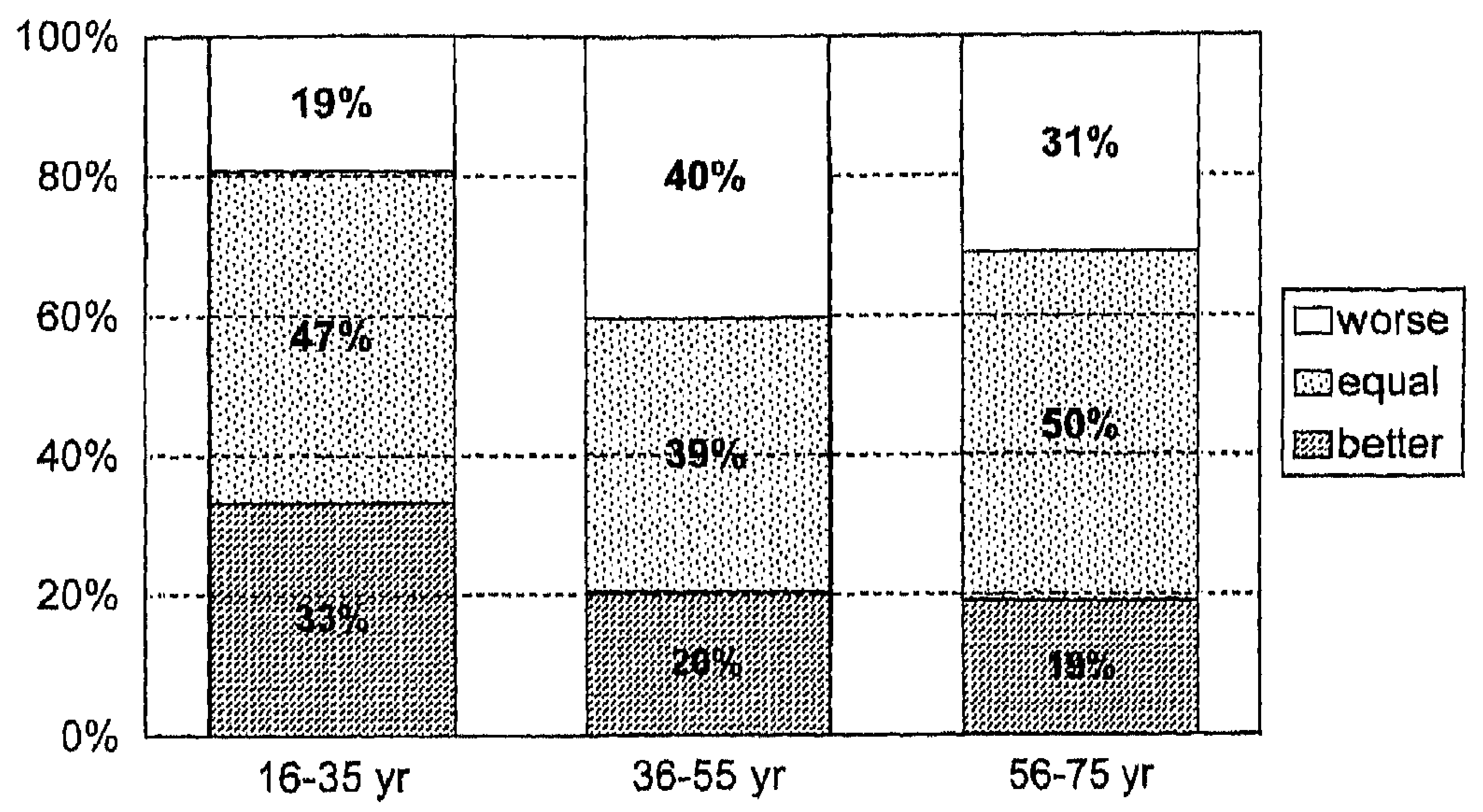

Figure 3 Memory for names and faces, in age groups $(n=545)$.

clearly more prevalent among the younger as well as among the older, while the middle age group shows a balanced distribution of optimists and pessimists. According to a Kruskal-Wallis three sample non-parametric test [Kruskal-Wallis Chi-square $(2)=10.4, p<0.01$ ] the differences between the age groups are significant.

Figure 3 shows the distribution of the answers across age groups to the second question in questionnaire 1, pertaining to memory for faces and names. Again the differences between age groups are significant [KruskalWallis Chi-square $(2)=20.6, p<0.001)$. Irrespective of age, less than half of the respondents - definitely fewer than was the case for memory of events (a difference that is significant according to the sign test for the whole group, as well as for the young and middle age groups, but not for the older age group) - think their memory for faces and names is neither better nor worse than that of most others they know. The tendency to think that your own memory for faces and names is better than that of most others you know is more prominent among the young, while for the middle and older age groups illusory pessimism is more common than illusory optimism.

One more question must be addressed with respect to questionnaire 1: does sex make a difference? In our sample, the number of men was about equal to the number of women. For events, no significant difference between men and women emerged [Mann-Whitney non-parametric two sample test, $p=0.18]$. For both sexes, it is true that considerably more respondents think their memory is better than that of most other people than there are respondents who think the reverse.

For memory of faces and names, there is a significant sex difference: women are more illusory optimistic, men are more illusory pessimistic [Mann-Whitney test, $p<0.001$. 


\section{Questionnaire 2}

Questionnaire 2 consisted of three questions. The first two were concerned with memory for faces and memory for names, separately. The results are shown in Table 2.

For both faces and names, the differences between men and women fail to reach significance. This contradicts the result from questionnaire 1 that women appeared to be more given to optimism with respect to their memory for faces and names than men. The results from questionnaire 2 indicate that both men and women show a marked tendency towards optimism with respect to their memory for faces, but not with respect to memory for names [Wilcoxon's signed rank tests show illusory optimism for faces $(p<0.001)$, but not for names $(p=0.61)]$. So, it does make a difference whether one is concerned with face or names: in both sexes, faces share the tendency towards illusory optimism for events. For memory of names, the results for both men and women are evenly balanced. These findings suggest that the indications in the first questionnaire for optimism among women for faces and names together, must almost certainly be attributed to such tendency for memory for faces. Moreover, it must be remembered that respondents to questionnaire 2 were all young. From the results of questionnaire 1, we already know that the tendency towards illusory optimism is more marked among the young than among older age groups.

Table 3, finally, shows the results of the third question in questionnaire 2 , i.e., the question whether respondents think their memory for

Table 2 Frequencies (and percentages) of responses to questions about memory for faces and memory for names, separately, by men $(n=28)$ and women $(n=34)$.

\begin{tabular}{lccrrr}
\hline & \multicolumn{2}{c}{ Faces } & & \multicolumn{2}{c}{ Names } \\
\cline { 2 - 3 } \cline { 6 - 6 } & Men & Women & & Men & Women \\
\hline Better & $13(46)$ & $17(50)$ & & $7(25)$ & $9(26)$ \\
Equal & $15(54)$ & $17(50)$ & & $11(39)$ & $16(47)$ \\
Worse & $0(0)$ & $0(0)$ & $10(26)$ & $9(27)$ \\
\hline
\end{tabular}

Table 3 Comparison between memory for faces and memory for names by sex $(n=62)$

\begin{tabular}{lccc}
\hline & Names better & Equal & Faces better \\
\hline Men & $8(29)$ & $2(7)$ & $18(64)$ \\
Women & $11(32)$ & $0(0)$ & $23(69)$ \\
Total & $19(31)$ & $2(3)$ & $41(66)$ \\
\hline
\end{tabular}


faces better or worse than their memory for names. Clearly, most respondents judge their memory for faces superior to their memory for names, while hardly anybody thinks their memory for faces and names is equally good or bad [Wilcoxon's symmetry test shows a marked preference for better memory for faces, $p<0.005$ ]. According to the respondents, memory for faces is not the same thing as memory for names. There is even a small negative correlation [Kendall's tau $=-0.19$, not significant], which in absolute size is about equal to the correlation between event memory and faces/names memory observed in questionnaire 1, viz. 0.22]. From this, one may again conclude that the second question in questionnaire 1 , in which memory for faces was lumped together with that for names, was not a very good one.

It remains to note that also for this question sex differences did not reach significance: both men and women think their memory for faces better than their memory for names. What makes a difference for subjective memory power - which, as mentioned earlier, is not the same thing as objective memory performance - is age rather than sex, with the young more given to illusory optimism for events and faces, but not for names, than the elderly.

\section{DISCUSSION}

Among the various types of evidence offered to triers of fact in legal cases, eyewitness reports are probably the most common. This makes the accuracy of autobiographical memory of witnesses of prime importance. The vast literature on this issue indicates that legal psychologists are well aware of this. There is, however, little evidence in the literature that they also acknowledge that eyewitness testimony, accurate or not, only matters in so far as triers of fact believe it.

Obviously, triers of fact do try to evaluate testimony offered to them. A witness' behavior and appearance are probably often used for this purpose, but, as earlier indicated, they should not. A witness' reputation may be used as a factor and at least in the Anglo-American tradition, the credibility of a witness may be challenged during cross-examination. This is sensible practice, although it is by no means fool-proof, as most adults are quite versed in lying and pretending. In the continental European legal tradition, challenging the credibility of a witness is more difficult, because rigorous cross-examination of witnesses is often not allowed by the courts.

The basic assumption of this study was that subjective ideas about what is possible and probable in human memory are among the most obvious standards by which triers of fact gauge the believability of eyewitness testimony. This, in turn, largely depends on what they think possible and 
probable in their own memory and how they think their own memory compares to that of most other people they know or, rather, think they know.

It is entirely possible that the memory of some people is considerably better or worse than that of some other people. However, if you are asked, as was done in this study, to compare your own memory to that of "most others you know", the prudent answer is that your memory power is probably about the same as that of most others. The reason for this is of a statistical nature: if you know virtually nothing of a distribution, the best prediction is the statistical mean. Yet, from the literature on self-serving biases (e.g., Greenberg, Pyszczynski and Solomon, 1982), we know that many do not seem to be aware of this statistical rule and tend to place themselves in the upper part of a distribution, when the attribute to be predicted is generally seen as a desirable quality. This is the 'illusory optimism' phenomenon.

To the best of our knowledge, no study has yet demonstrated illusory optimism for memory, but some studies came close to it. For example, the work of Fischhoff, Slovic, and Lichtenstein (1977) demonstrates that people display unwarranted certainty in their answers to general-knowledge questions. That is, people are overconfident in the correctness of their answers, even if these answers are wrong. But, of course, overconfidence in memory for general facts does not necessarily imply overconfidence for autobiographical 'facts', which leaves open the question whether there are indications that such overconfidence generalizes to autobiographical memory. Our data indicate that there is, indeed, a tendency for illusory optimism and thus overconfidence in memory for events. This is particularly true for young respondents. The same appears to be true for the elderly, but we hasten to point out that our subsample of the elderly only contained 42 respondents. The middle age group $(n=109)$ on average showed no tendency toward illusory optimism.

Also for faces - but not for names - young respondents on average show a marked tendency toward illusory optimism. The implication is that among young triers of fact, many may tend to underestimate the validity of eyewitness testimony offered to them. In the continental European legal system professional judges are the triers of fact. Most of them will not be very young, but note that our subsample of young respondents contained a considerable number of 26-35 year olds, at which age at least in our country you may already serve as a junior judge.

On the other hand, there is also a minority of at least 10 percent in all age groups with a tendency towards illusory pessimism with respect to events. As triers of fact both optimists and pessimists are equally troublesome. Perhaps, in the Anglo-American system, one could ask prospective jurors during voir dire the same or similar questions as those we asked 
our respondents, and exclude those who show illusory optimism and/or its opposite.

Let us now consider some of the results in more detail. First, those with respect to age differences in subjective memory of events. That the older subgroups of our sample do not more often report that they think that their memory for events is worse than that of most others (see Figure 2), is somewhat surprising in the light of the result reported by Ponds (1998) that age-related decline in subjective cognitive functioning starts at the age of 50 and steadily increases afterwards. On the basis of this information one might expect a tendency toward illusory pessimism among the elderly. However, Woodruff-Pak (1997) contradicts Ponds, saying that metamemory, i.e., knowing about remembering and in particular about one's own capacities for memory, is stable across the adult life span. In any case, our questionnaire did not ask the respondents to compare their memory with that of just anybody, but with that of "most other people you know - members of your family, friends and colleagues." If we assume that most people, and in particular the elderly, mostly know people of their own age, one would not expect much illusory pessimism even if one sides with Ponds.

One may wonder whether it is not in fact the case that memory declines with age. The empirical evidence for this in healthy people is somewhat confusing. Summarizing what was known about the relation between memory performance and age, Loftus in 1979 concluded "that recall and recognition improves with age up to a point, say about fifteen or twenty years old, and a decline may begin to occur in the later years, perhaps the age of sixty years" (Loftus, 1979: 160). More recently LaRue (1992: 57) wrote that "on many everyday tasks as well as many artificial ones, older subjects often perform worse than younger comparison groups," due to "shallower and less efficient encoding activities in old age." So, maybe it is not (long term) memory that declines with age, but rather the "patience with practicing" among the elderly (Woodruff-Pak, 1997: 229). Finally, Schacter (1996: 283) noted that "decades of research leave little doubt that aging can impair memory," which he attributes mostly to athrophy or shrinkage in the frontal regions of the brain. He is, however, not precise about the average age on which such decline may be expected. From the context we gather that he was talking about the very old, as were LaRue and Woodruff-Pak. If so, we remind the reader that the group of really old people in our sample $(>65)$ only contained 12 respondents. All this serves to argue that there probably is no strong factual basis for expecting 'illusory pessimism' among the elderly in our sample, while at the same time expecting a tendency for pessimism among the very old, which has a factual basis. 
One also wonders why illusory pessimism among the elderly is evident for faces and names (see Figure 3), but not for events. One might surmise that in general, i.e. irrespective of age, memory for events is more robust than memory for faces and, perhaps even more so, for names. There is no solid evidence for this, but if most people think this to be the case, this may explain in part why many respondents think their memory for faces and names is more age-sensitive than their memory for events. This, however, is in part contradicted by the fact that illusory optimism among the young is about equal for names and faces as for events, indicating that they at least do not see much difference between their memory for events and their memory for faces and names.

A second issue deserving some comment is our finding that there was a sex difference for memory of faces and names, but not for events. Is there any factual basis for this? Women on average outperform men in verbal tasks, i.e., reading ability and reading comprehension (Geary, 1998). The same appears to be the case for facial processing (Geary, 1998), which might explain the difference. But why would this be the case? Once more one might call on a conjecture that many will be inclined to feel along with, viz. that women are more sensitive to personal information than men. If this is true, then, perhaps, we should not without further ado attribute more illusory optimism to women than men, for possibly women are in fact better than men at remembering faces and names.

Is there in the literature any evidence for gender differences in memory? Loftus (1979: 156), speaking about witness accuracy and reviewing the evidence available at the time, concluded that the results on this matter are equivocal: "Some studies of sex differences have shown that females perform better than males (...), while others have shown that males perform better than females (...); still others indicate no difference in the accuracy of women and men (...)." To accommodate these confusing results, she submits the hypothesis that perhaps "both women and men pay more attention to items that catch their interest and consequently store more and better information in memory about those items." There is, indeed, some evidence for this (Powers, Andriks and Loftus, 1979). However, if we now invoke the Loftus hypothesis to explain our data and assume that women pay more attention to faces and names than men, this explanation would be circular as there is as yet no independent corroboration for this difference. Moreover, when we surveyed - by means of questionnaire 2 - a group of young people about their memory for faces and names separately, we found for neither of these a difference between men and women.

In conclusion, one might say that at least half or even more (as in the case of memory for events) of our respondents in their answers to our questions demonstrate a sensible realism with respect to other people's memory powers. But this good news is mixed with the bad that about half 
of our respondents gave something else that the prudent answer. Among those, the majority of either sex showed a tendency toward illusory optimism with respect to memory for events and for faces. Those showing a tendency toward illusory pessimism were a minority, but by no means rare. The optimists as well as the pessimists should not altogether be trusted when serving as triers of fact in legal cases.

We realize that our data only scratch the surface of the issue raises in the introduction, but they do show that there is indeed a case to answer. Now that the issue is raised, more research will be needed to clarify it. To our minds, the obvious next step would be to present subjects with prototypes of particular memory tasks, let them inspect these for a relatively short period of time and next ask them (a) to predict their own future performance on a series of those tasks, and (b) to predict how 'most other people they know' on average will perform on those. One could proceed to testing the subjects on a series of similar memory tasks, and see how accurate those predictions are - not very accurate, we expect on the basis of Ponds results mentioned in the introduction - and what predicts the subjects' actual performance better: their own Performance or their prediction of other people's performance. Our prediction is that the latter will be the case.

\section{References}

Deffenbacher, K. A. (1980). Eyewitness accuracy and confidence. Law and Human Behavior, 4, 243-260.

Farah, M. J., Wilson, K. D., Drain, M. and Tanaka, J. N. (1998). What is "special" about face recognition? Psychological Review, 105, 482-498.

Fischhoff, B., Slovic, P. and Lichtenstein, S. (1977). Knowing with certainty: The appropriateness of extreme confidence. Journal of Experimental Psychology: Human Perception and Performance, 3, 552-564.

Geary, D. C. (1998). Male, Female. Washington, DC: American Psychological Association.

Gilewski, M. J. and Zelinski, E. M. (1986). Questionnaire assessment of memory complaints. In L. W. Poon (Ed.), Handbook of Clinical Memory Assessment in Older Adults (pp. 93-107). Washington, DC: American Psychological Association.

Greenberg, J., Pyszczynski, T. and Solomon, S. (1982). The self-serving attributional bias: Beyond self-presentation. Journal of Experimental Social Psychology, 18, 56-67.

Hoorens, V. (1993). Self enhancing and superiority biases in social comparison. In W. Stroebe and M. Hewstone (Eds.), European Review of Social Psychology, Volume 4 (pp. 113-139). Chicester: Wiley.

LaRue, A. (1992). Aging and Neuropsychological Assessment. New York: Plenum.

Loftus, E. F. (1979). Eyewitness Testimony. Cambridge, MA: Harvard University Press.

Nisbett, R. E. and Ross, L. (1980). Human Inference: Strategies and Shortcomings of Social Judgment. Englewood Cliffs: Prentice-Hall.

Ponds, R. W. (1998). Forgetfulness and Cognitive Aging: Prevalence, Characteristics and Determinants. Maastricht: Doctoral Thesis Maastricht University.

Pöppel, E. (1988). Mindworks. New York: Hartcourt Brace Javanovich.

Powers, P. A., Andriks, J. L. and Loftus, E. F. (1979). The eyewitness accounts for females and males. Journal of Applied Psychology, 64, 339-347. 
Schacter, D. J. (1995). Memory Distortion: How Minds, Brains, and Societies Reconstruct the Past. Cambridge, MA: Harvard University Press.

Schacter, D. J. (1996). Searching for Memory. New York: Basic Books.

Wieskrantz, L. (1997). Consciousness Lost and Found. Oxford: Oxford University Press.

Winkel, F. W. and Vrij, A. (1990). Interaction and impression in a cross-cultural dyad: Frequency and meaning of culturally determined gaze behavior in a police interview setting. Social Behavior: International Journal of Applied Social Psychology, 5, 335-350.

Woodruff-Pak, D. S. (1997). The Neuropsychology of Aging. Oxford: Blackwell. 